\title{
Ligand Binding Mode to Duplex and Triplex DNA Assessed by Combining Electrospray Tandem Mass Spectrometry and Molecular Modeling
}

\author{
Frédéric Rosu, ${ }^{a}$ Chi-Hung Nguyen, ${ }^{b}$ Edwin De Pauw, ${ }^{a}$ \\ and Valérie Gabelica ${ }^{a}$ \\ ${ }^{a}$ Laboratory of Mass Spectrometry, University of Liège, Liège, Belgium \\ ${ }^{\mathrm{b}}$ UMR 176 CNRS-Institut Curie, Laboratory of Pharmaceutical Chemistry, Research Section, Orsay, France
}

In this paper, we report the analysis of seven benzopyridoindole and benzopyridoquinoxaline drugs binding to different duplex DNA and triple helical DNA, using an approach combining electrospray ionization mass spectrometry (ESI-MS), tandem mass spectrometry (MS/MS), and molecular modeling. The ligands were ranked according to the collision energy $\left(\mathrm{CE}_{50}\right)$ necessary to dissociate $50 \%$ of the complex with the duplex or the triplex in tandem MS. To determine the probable ligand binding site and binding mode, molecular modeling was used to calculate relative ligand binding energies in different binding sites and binding modes. For duplex DNA binding, the ligand-DNA interaction energies are roughly correlated with the experimental $\mathrm{CE}_{50}$, with the two benzopyridoindole ligands more tightly bound than the benzopyridoquinoxaline ligands. There is, however, no marked AT versus GC base preference in binding, as supported both by the ESI-MS and the calculated ligand binding energies. Product ion spectra of the complexes with triplex DNA show only loss of neutral ligand for the benzopyridoquinoxalines, and loss of the third strand for the benzopyridoindoles, the ligand remaining on the duplex part. This indicates a higher binding energy of the benzopyridoindoles, and also shows that the ligands interact with the triplex via the duplex. The ranking of the ligand interaction energies compared with the $\mathrm{CE}_{50}$ values obtained by MS/MS on the complexes with the triplex clearly indicates that the ligands intercalate via the minor groove of the Watson-Crick duplex. Regarding triplex versus duplex selectivity, our experiments have demonstrated that the most selective drugs for triplex share the same heteroaromatic core. (J Am Soc Mass Spectrom 2007, 18, 1052-1062) (c) 2007 American Society for Mass Spectrometry

$\mathrm{D}$ NA-binding reagents exhibit a high potential as chemotherapeutic drugs, and many approved anticancer therapies include molecules that are DNA binders. These agents interfere with gene replication or transcription in proliferating cells such as cancer cells [1]. However, classical chemotherapies are still very toxic for healthy cells as well, and cause many unwanted effects. One of the most challenging goals is, therefore, the design of molecules that bind to nucleic acids with high structural and sequence selectivity to target specific disease-related genes. Triplex DNA formation is one such strategy to target specific DNA sequences [2-6]. Triple helices of polyribonucleotides were first observed in 1957 [7]. DNA triplexes are formed when a DNA strand called the antigene binds to a duplex (the gene) in its major groove. Combining

Address reprint requests to Dr. V. Gabelica, Laboratoire de Spectrométrie de Masse, Université de Liège, 3 allée de la chimie, 4000 Liège, Belgium. E-mail: v.gabelica@ulg.ac.be triplex-specific ligands with antigenes is, therefore, a means of targeting genes more specifically than with duplex-binding agents $[8,9]$.

The interaction between the drugs and the nucleic acids can be studied when the physical properties of the ligand molecule change upon binding, and are easily monitored. Spectroscopic techniques (UV-visible absorption spectroscopy, fluorescence, circular dichroism) [10, 11], equilibrium dialysis [12, 13], surface plasmon resonance [14, 15], or calorimetric techniques [16, 17] are commonly used to study ligand-DNA interactions. Electrospray ionization mass spectrometry has also shown its potential in the evaluation of DNA-ligand binding for more than a decade [18-26]. The study of the interaction of families of ligands with particular DNA structure like duplex and quadruplex structures can be made quickly. In these ESI-MS assays, the relative intensities of the free DNA and of the complexes are taken as a picture of the relative abundances of these species 

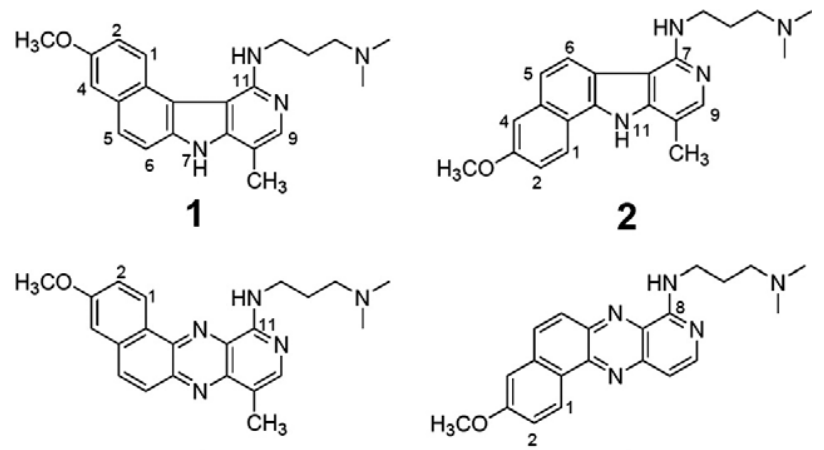

3
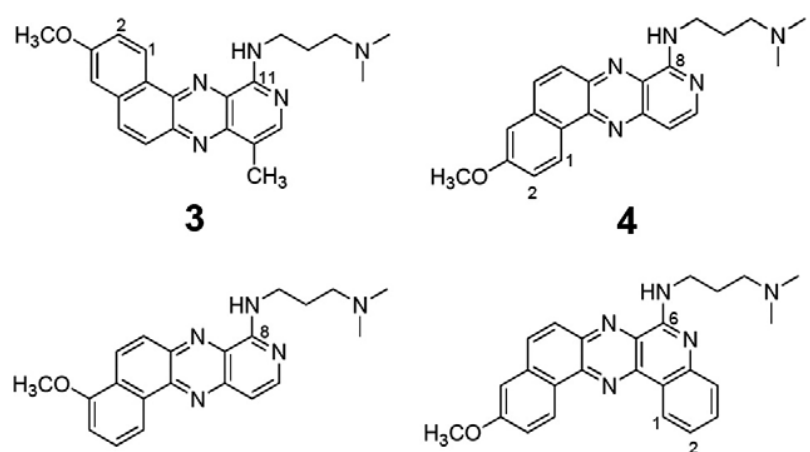

5

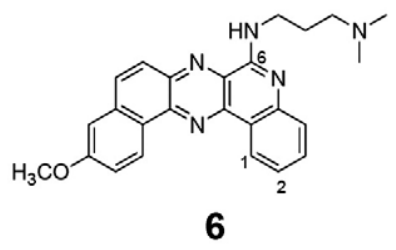

6

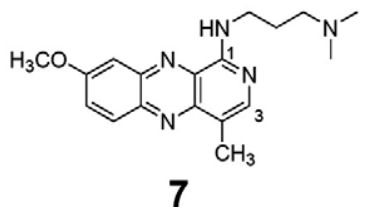

Scheme 1

in solution [27]; this approach has proven valid when the ESI-MS data are compared with classical spectroscopic techniques [28-32].

The present paper reports for the first time the use of ESI-MS and ESI-MS/MS to study triplex DNA with noncovalently bound ligands. The ligand structures are shown in Scheme 1. The benzopyridoindole (BPI) ligands 1 and 2 are representatives of the benzo[e]pyridoindole (BePI, 1) and of the benzo[ $g$ ]pyridoindole (BgPI, 2) families [33, 34]. These molecules interact with duplex DNA [35], triplex DNA [34, 36, 37], and inhibit topoisomerases I and II [38]. Benzo[f]pyridoquinoxaline derivatives (BPQs, 3-5) were developed to target triplex DNA more specifically $[39,40]$, while pyridoquinoxaline derivatives $(P Q, 7)$ served to assess the role of the extra benzo ring. All these ligands are DNA intercalators [34, 41, 42]. Encouraged by the promising results obtained with BPQs, a new benzoquinoquinoxaline (BQQ, 6), was designed to optimize triplex interaction, synthesized, and successfully tested [43].

Our goal here was to evaluate binding affinity and selectivity of these ligands for DNA duplexes of varying GC content, and for a triplex DNA, and to evaluate how tandem mass spectrometry (MS/MS) combined with molecular modeling can be used to obtain information on the ligand binding site. MS/MS data are interpreted using the transition-state theory concepts [44-46]. The dissociation rate of the complex depends (1) on an enthalpy term, which is the energy difference between the reactant (i.e., intact complex) and the transition-state

(the state at which dissociation becomes irreversible), (2) an entropy term, which reflects the probability of the dissociation pathway and which depends on the mechanism, and (3) on the internal energy. Consequently, when internal energy and dissociation pathways are the same, the dissociation rate should be related to the interaction energy in the complex. For small complexes, these interaction energies can be calculated by quantum chemical methods, but for large complexes such as those DNA complexes studied here, molecular mechanics approaches are more practical. We will show here that, when the experimental MS/MS relative dissociation rates are compared with relative interaction energies calculated for different structural models, some structural interpretation can be made on the ligand binding mode.

\section{Materials and Methods}

\section{Materials}

The self-complementary duplexes Dk33 (dCGTAAATTTACG) $)_{2}$ Dk66 (dCGCGAATTCGCG) $)_{2}$, and Dk100 (dCGCGGGCCCGCG) ${ }_{2}$ were prepared in 100 $\mathrm{mM}$ aqueous $\mathrm{NH}_{4} \mathrm{OAc}$. All stock solutions were diluted to $50 \mu \mathrm{M}$ at neutral $\mathrm{pH}$. The triple helical DNA was prepared in $150 \mathrm{mM} \mathrm{NH} \mathrm{NH}_{4} \mathrm{OAc}$ acidified with acetic acid $(\mathrm{pH}=5.5)$, as previously described [47]. The triplex was formed from single strands dCCTTTTCTCTTTCC (T1), dGGAAAGAGAAAAGG (T2), which constitute a Watson-Crick duplex (T1-T2), and the strand dCCTTTCTCTTTTCC (T3), which is the antigene strand. Sequence T3 is the reverse of sequence T1. The oligonucleotides were purchased from Eurogentec (Seraing, Belgium) and used without further purification.

The synthesis of the benzo[e]pyridoindole 1 (CA: 125974-68-7) and the benzo[f]pyridoindole 2 (CA: 170890-29-6) was described in 1990 [33], the synthesis of the benzo[f]pyridoquinoxaline 3 (CA: 165548-08-3), benzo $[h]$ pyridoquinoxalines 4 (CA: 165548-10-7), and 5 (CA: 165548-11-8) and of the pyridoquinoxaline 7 (CA: 165548-02-7) was described in 1995 [39], and the synthesis of the benzo[f]quinoquinoxaline 6 (CA: 373595-26-7) was reported in 1998 [43]. The drug stock solutions were 100 or $200 \mu \mathrm{M}$ in bi-distilled water.

For ESI-MS, drug-duplex mixtures of $10 \mu \mathrm{M}$ DNA and $15 \mu \mathrm{M}$ drug were prepared in $150 \mathrm{mM} \mathrm{NH}_{4} \mathrm{OAc}$ and $15 \%$ methanol. The small proportion of methanol used $(15 \%)$ does not disturb the particular DNA structures used in our assay as verified by CD (data not shown), and the high ionic strength used prevents the AT-rich duplex and the triplex from unfolding. The concentrations of the DNA stock solutions were checked no more than 3 days before the ESI-MS experiments by UV absorbance measurements. 


\section{Mass Spectrometry}

ESI-MS experiments were performed on a LCQ instrument (Finnigan LCQ ion trap instrument (ThermoFinnigan, San Jose, CA) equipped with its standard heated capillary electrospray source or a Q-TOF Ultima Global (Micromass, now Waters, Manchester, UK) with its standard ESI source. On the LCQ, the needle voltage was set to $-3.9 \mathrm{kV}$. The capillary was heated to $180{ }^{\circ} \mathrm{C}$ and the applied potential was $-10 \mathrm{~V}$. The skimmer was at ground potential and the tube lens offset was maintained at $40 \mathrm{~V}$. On the Q-TOF, in negative ion mode, the capillary voltage was set to $-2.2 \mathrm{kV}$, the cone voltage to $-35 \mathrm{~V}$, and the RF Lens1 to $-70 \mathrm{~V}$. The hexapole collision voltage of $10 \mathrm{~V}$ was used for full scan MS. The affinity of the drug for a given structure is deduced from the concentration of bound ligand per DNA molecule ${ }^{\circ}\left[27,{ }^{\circ} 30\right] .{ }^{\circ}$ The $^{\circ}$ concentration ${ }^{\circ}$ of $^{\circ}$ bound ${ }^{\circ}$ ligand per DNA molecule is calculated from the relative intensities of the free DNA and of the complexes using the following eq 1

$$
\begin{aligned}
& \text { [Bound Ligand] }=\mathrm{C}_{0} *\left(\mathrm{I}_{(1: 1)}+2 \mathrm{I}_{(2: 1)}+3 \mathrm{I}_{(3: 1)}\right) /\left(\mathrm{I}_{(D N A)}\right. \\
& \left.+\mathrm{I}_{(1: 1)}+\mathrm{I}_{(2: 1)}+\mathrm{I}_{(3: 1)}\right)
\end{aligned}
$$

where $C_{0}$ is the starting DNA concentration (expressed in duplex or triplex concentration), $\mathrm{I}_{(\mathrm{DNA})}$ is the relative intensity of the free DNA, and $\mathrm{I}_{(\mathrm{n}: 1)}$ are relative intensities of the complexes ( $n$ drug molecules bound to one DNA structure). The concentrations of bound ligand were found independent on the instrument used.

MS/MS experiments were all performed on the Q-TOF Ultima Global. This choice was made for two reasons. First, the mass range of the LCQ is limited to $2000 \mathrm{~m} / \mathrm{z}$ and some triple helix fragments are observed at $\mathrm{m} / \mathrm{z}>2000$. Second, thanks to the higher-energy collision regime of the Q-TOF, direct noncovalent bond breaking is favored compared with rearrangement re-

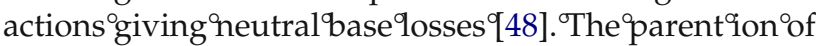
interest was selected in the first quadrupole, and the hexapole collision voltage was varied. The argon pressure in the collision hexapole $\left(3.0 \times 10^{-5} \mathrm{mbar} \pm 5 \%\right)$ and the source pressure $(2.70 \mathrm{mbar})$ were carefully kept constant. Source block and desolvation temperatures were set to $70^{\circ} \mathrm{C}$ and $100{ }^{\circ} \mathrm{C}$, respectively.

\section{Molecular Modeling}

Hyperchem 7.5 software (Hypercube, Inc.) was used with AMBER99 force field. The starting duplex $\mathrm{d}$ (CGCGAATTCGCG) ${ }_{2}$ was the solution structure de-

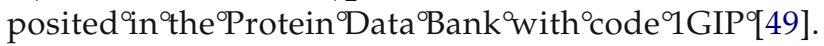
As these ligands are known to bind DNA by intercalation $[34,41,42]$, three ${ }^{\circ}$ different ${ }^{\circ}$ intercalation ${ }^{\circ}$ sites $^{\circ}$ on the duplex $d(\text { CGCGAATTCGCG })_{2}$ have been independently generated as follows. First, an increase of the space between two base pair by $3.4 \AA$ was performed. Second, the twist angle of the helix (in- cluding one of the two base pair involved in the intercalation site) was decreased by 10 degrees to compensate the change in the distance between the sugar-phosphate backbones. These parameters were chosen based on the structures of complexes between duplex DNA and intercalators found in PDB entries $2 \mathrm{DES}^{\circ}[50]^{\circ}$ and $^{\circ} 1 \mathrm{D} 10^{\circ}[51] .^{\circ}$ Finally, ${ }^{\circ}$ local $^{\circ}$ geometry optimization including the two base pairs and the backbone involved in the intercalation site and in the sugar-phosphate surrounding the site was performed to relax the system. The intercalation sites were $\mathrm{CG} * \mathrm{CG}, \mathrm{CG} * \mathrm{AT}$, and AT*AT. The global effect of the intercalation site on the duplex was the increase of the dimension of the grooves due to the decrease of the twisting angle of the two base pairs of the intercalating site. Each drug was manually docked in the intercalation site in different orientations as described in the text below, and energy minimized in the force field generated by the duplex until an energy gradient of $0.05 \mathrm{kcal} /(\mathrm{mol} . \AA)$ was reached (Polak-Riebiere conjugate gradient algorithm). The maximum gradient of the generated ligand-DNA was never higher than $0.3 \mathrm{kcal} /\left(\mathrm{mol} . \AA{ }^{\circ}\right)$, which is satisfactory (the DNA without drug has at a gradient of 0.2 $\mathrm{kcal} /(\mathrm{mol} . \AA))$ and indicated that no steric clash problem is encountered. The same methodology as for the duplex was used to generate the intercalation sites and calculate the interaction energies between the drugs and the triplex. The starting triplex model was generated using a smaller triple helical DNA (seven triplets) based on the NMR solution structure of a pyrimidine-purine-pyrimidine DNA triplex (PDB entry $^{\circ}$ 149D $)^{\circ}[52] .{ }^{\circ}$ Two $^{\circ}$ intercalation ${ }^{\circ}$ sites $^{\circ}$ between $^{\circ}$ the base-triplet were generated: CGC-TAT and TATTAT.

The interaction energy was calculated using the following eq 2 :

$$
\mathrm{E}_{\text {int }}=\mathrm{E}_{(\text {(complex) }}-\mathrm{E}_{(\text {(Ligand) }}-\mathrm{E}_{(\mathrm{DNA})}
$$

here $\mathrm{E}_{\text {(complex) }}$ is the complex energy, $\mathrm{E}_{\text {(ligand) }}$ is the energy of the ligand with its geometry in the complex, and $\mathrm{E}_{(\mathrm{DNA})}$ is the energy of the free DNA (duplex or triplex).

\section{Results and Discussions}

\section{ESI-MS Determination of Ligand Selectivity}

The sequence and structural selectivities of the seven

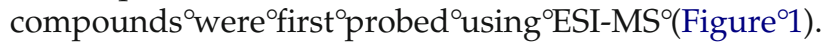
Figure ${ }^{\circ} 1 a^{\circ}$ shows ${ }^{\circ}$ the ${ }^{\circ}$ ESI-MS ${ }^{\circ}$ spectra ${ }^{\circ}$ obtained ${ }^{\circ}$ with $^{\circ}$ the duplex d(CGCGGGCCCGCG) 2 (DK100) or the triplex and ligand 6 . The 1:1 and 2:1 complex are detected. The amount of ligand 6 bound to the triplex under the experimental conditions is higher than to the duplex. We have previously shown a methodology to quantify the amount of bound ligand in DNA-ligand mixtures 


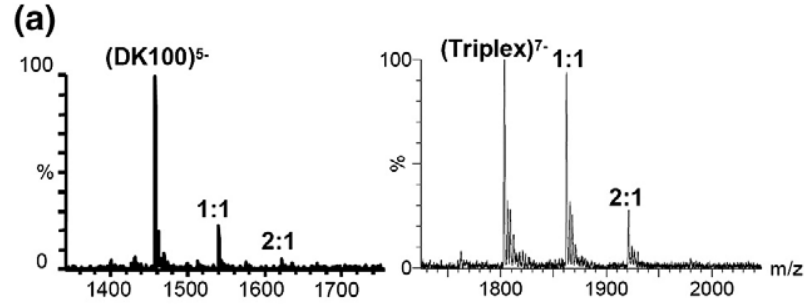

(b)

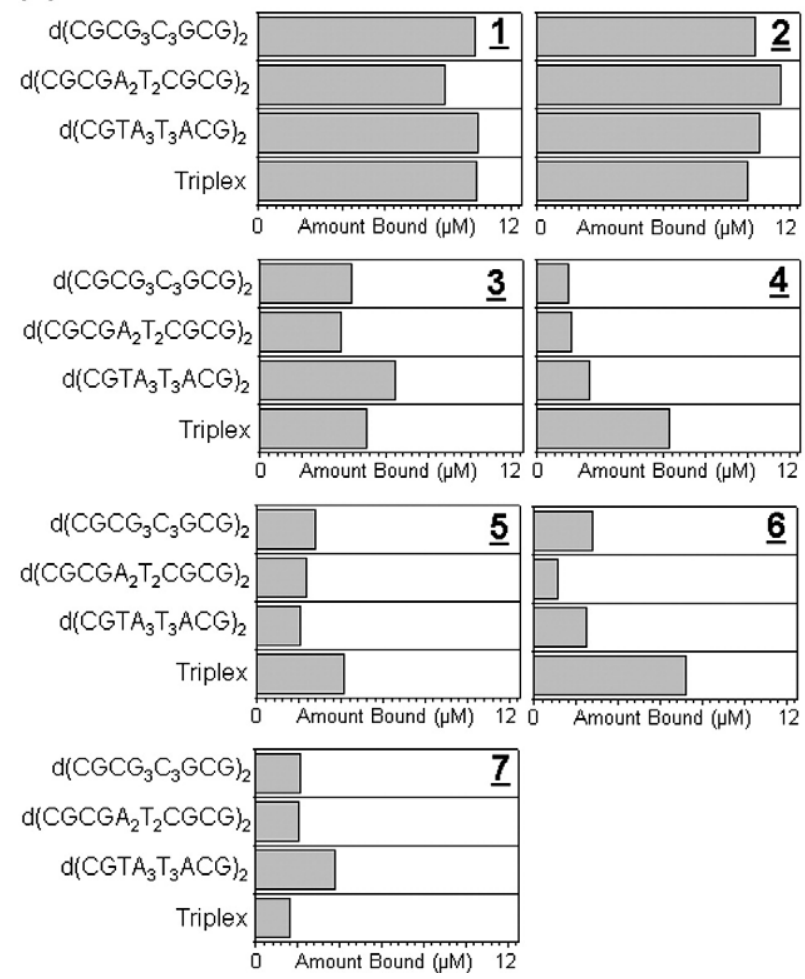

Figure 1. ESI-MS screening of ligand-duplex and ligand-triplex binding. (a) Representative ESI-MS spectra with a duplex and triplex DNA: ESI-MS spectra of solution containing $10 \mu \mathrm{M}$ DNA (duplex DK100 on the left and triplex on the right, see the Materials and Methods section for the sequences) and $15 \mu \mathrm{M}$ ligand 6. (b) Relative ligand affinities for the different DNA structures: Concentration of ligand bound (in $\mu \mathrm{M}$ bound out of 15 $\mu \mathrm{M}$ total ligand added to $10 \mu \mathrm{M}$ DNA) to three duplexes and the triplex.

using ${ }^{\circ} \mathrm{ESI}^{-\mathrm{MS}^{\circ}}[27]^{\circ}{ }^{\circ}$ The $^{\circ}$ methodolog $^{\circ}{ }^{\circ}{ }^{\circ}{ }^{\circ}$ based $^{\circ}$ on $^{\circ}$ the assumption that the relative intensities of the free DNA and of the complexes are proportional to the relative abundances in solution. This assumption has been shown valid in the case of double-stranded DNA complexed ${ }^{\circ}$ with $^{\circ}$ minor $^{\circ}$ groove ${ }^{\circ}$ binders ${ }^{\circ}\left[27\right.$, ,53]. The ${ }^{\circ}$ equilibrium binding constants for the 1:1 and 2:1 complexes with 6 and the triplex measured by ESI-MS were $\mathrm{K}_{1}=$ $1.2 \times 10^{5} \mathrm{M}^{-1}, \mathrm{~K}_{2}=3.9 \times 10^{4} \mathrm{M}^{-1}$, respectively. In comparison the values of the binding constants for the 1:1 and 2:1 complexes with 6 and the duplex were $\mathrm{K}_{1}=$ $3.2 \times 10^{4} \mathrm{M}^{-1}$ and $\mathrm{K}_{2}=3.7 \times 10^{4} \mathrm{M}^{-1}$. This example shows the potential of ESI-MS to detect and quantify multiple drug-DNA stoichiometries present at equilibrium in solution.
The calculated amounts of ligand bound to the different ${ }^{\circ} \mathrm{DNA}{ }^{\circ}$ structures ${ }^{\circ}$ are ${ }^{\circ}$ summarized ${ }^{\circ}{ }^{\circ}{ }^{\circ}$ Figure ${ }^{\circ} 1 \mathrm{~b}$. All drugs interact with the three DNA duplexes. Although intercalators usually show a preference for GC base pairs, this is not the case here, where even a small preference for AT-rich sequences is observed for some ligands, ${ }^{\circ}$ in $^{\circ}$ agreement ${ }^{\circ}$ with $^{\circ}$ footprinting ${ }^{\circ}$ studies ${ }^{\circ}[36]$. The two benzopyridoindoles, 1 and 2, have the highest duplex and triplex affinities compared with the other drugs. However, the BPI ligands, (1 and 2 ), show no marked selectivity for the triple helix compared with duplex DNAs. Ligands 4 and 6 show substantial selectivity for the triplex while ligand 5 shows moderate selectivity. The aromatic rings of these three ligands share a common tetracyclic core. Ligands 4 and 5 belong to the 8 -amino-benzo[f]pyrido[3,4-b]quinoxaline family and are much more selective than 3 (11-amino-benzo[f]pyrido[4,3-b]quinoxaline), where the benzene ring is linked to the other side on the quinoxaline. Ligand 7 , which has the smallest heteroaromatic ring, has the lowest affinity for both DNA structures. Taken together, these observations suggest that the shape of the heteroaromatic ring system of these drugs, therefore, plays an important role in stacking interactions with the base triplets.

\section{ESI-MS/MS and Molecular Modeling on the (1:1) Duplex-Ligand Complexes}

In the case of duplex-drug complexes, we have previously classified drugs in three categories based on their dissociation pattern in tandem mass spectrometry experiments 954$]$. The first $^{\circ}$ group includes ${ }^{\circ}$ drugs ${ }^{\circ}$ for ${ }^{\circ}$ which the complex dissociates mainly via the loss of a neutral drug. For the second group, the complex dissociates mainly via the loss of a negatively charged drug, and for the third group via the separation of the strands (noted ss), which share the available charges and some drug molecule could stick on both strands. Here we have performed MS/MS experiments on the 1:1 (DrugDk66) ${ }^{\circ} \mathrm{Complex}^{\circ}\left(\right.$ Figure $\left.^{\circ}\right){ }^{\circ}{ }^{\circ}$ All ${ }^{\circ}$ the ${ }^{\circ}$ complexes $^{\circ}$ with ${ }^{\circ}$ each of the seven drugs dissociate mainly via the loss of a neutral drug.

$$
[\mathrm{DK} 66+\text { Drug }]^{5-} \rightarrow[\mathrm{DK} 66]^{5-}+\text { Drug }
$$

In the case where the dissociation mechanism is the same for a series of ligands, the $\mathrm{CE}_{50}$ values are directly related to the activation energy of dissociation. This condition is fulfilled here as (1) the dissociation pathways are identical and (2) the parallel dissociation curves indicate similar activation entropies. Moreover, if the dissociation involves the loss of neutral ligand from the charged duplex, which is the case here, the activation energy is more likely to be proportional to the ${ }^{\circ}$ ligand ${ }^{\circ}$ binding ${ }^{\circ}{ }^{\circ}$ engy ${ }^{\circ}[54]$.

The dissociation pattern observed for all ligands is the same as for the drugs of the first group such as 
(a)
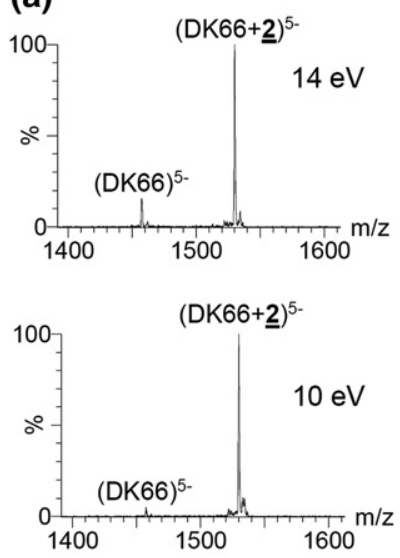

(b)
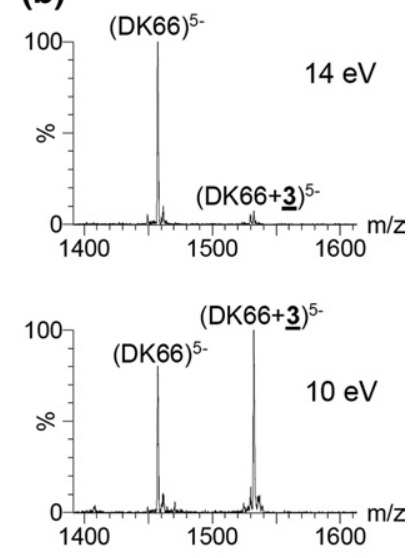

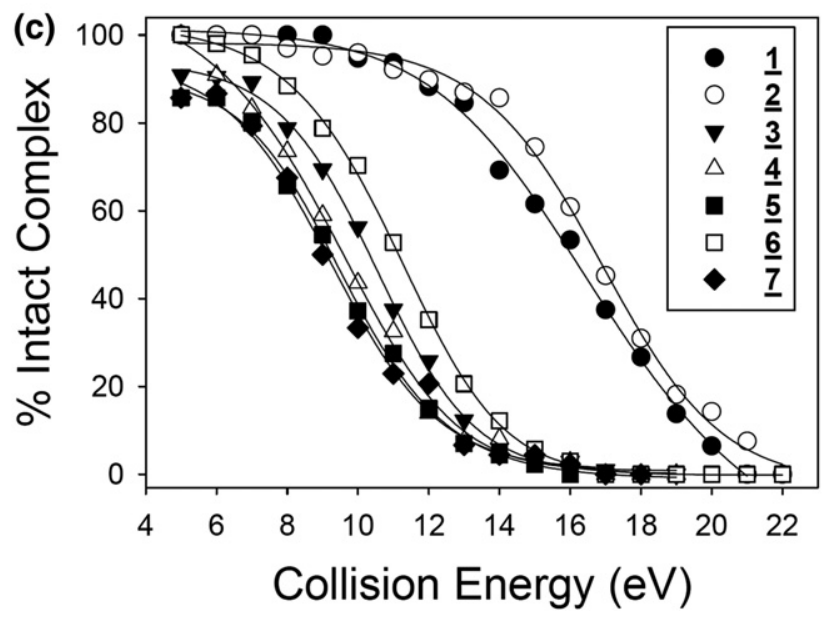

Figure 2. ESI-MS/MS experiments on $[1: 1]^{5-}$ complexes with the duplex DK66. (a) Representative MS/MS spectra obtained with ligands 2 (left) and 3 (right), using collision energies of 10 and $14 \mathrm{eV}$. The argon pressure inside the hexapole collision cell was $3.010^{-5}$ mbar. (b) MS/MS breakdown curves of different intercalator drugs with the d(CGCGAATTCGCG $)_{2}$ (Dk66) duplex. The \% of intact complex was calculated using eq 4 for each collision energy.

cryptolepine, proflavine, daunomycin, and doxorubi$\operatorname{cin}^{\circ}[54] .{ }^{\circ}$ Figure ${ }^{\circ} 2 a^{\circ}{ }^{\circ}$ learly ${ }^{\circ}$ shows ${ }^{\circ}$ the ${ }^{\circ}$ larger ${ }^{\circ}$ collision energy necessary to dissociate the complexes with the BgPI 2 compared with the BPQ 3. At $14 \mathrm{eV}$, the complex with 3 is nearly completely dissociated while only $15 \%$ of the complex with 2 is dissociated. Figure ${ }^{\circ} 2 \mathrm{~b}^{\circ}$ represents ${ }^{\circ}$ the ${ }^{\circ} \mathrm{MS} / \mathrm{MS}^{\circ}$ dissociation $^{\circ}$ curves obtained for all ligands.

The percentage of intact complex is calculated using the following eq 4

$$
\% \text { Complex }=\frac{\mathrm{I}_{\left([\mathrm{DK} 66+\mathrm{Drug}]^{5-}\right)}}{\mathrm{I}_{\left(\left[\mathrm{DK} 66+\mathrm{Drug}^{5-}\right)\right.}+\mathrm{I}_{\left(\mathrm{DK} 66^{5-}\right)}}
$$

The competitive dissociation of the duplex into the single strands $\left(\mathrm{ss}^{3-}\right.$ and $\mathrm{ss}^{2-}$ ) is only observed at collision energies $>18 \mathrm{eV}$, so this fragmentation chan- nel does not perturb the ordering of $\mathrm{CE}_{50}$. The two BPI ligands 1 and 2 leave the duplex at higher energy than the quinoxaline derivatives (3-7). Among the quinoxaline derivatives, 6 has the largest interaction energy with its binding site on the duplex (since higher collision energy is needed to dissociate the complex as compared to the other BPQ drugs).

We performed molecular modeling to compare the interaction energies of a drug with different binding site sequences on duplex d(CGCGAATTCGCG) ${ }_{2}$ and to correlate the calculated interaction energies to the relative $\mathrm{CE}_{50}$ values obtained by MS/MS. Several groups have examined the molecular recognition and the dynamics of drug-DNA interactions using molecular modeling ${ }^{\circ}[55-57] .{ }^{\circ} \mathrm{As}^{\circ}$ the ${ }^{\circ}$ energetic ${ }^{\circ}$ parameters ${ }^{\circ} \mathrm{calcu}-$ lated by molecular modeling are related to the gas phase, the calculation using molecular modeling of the energetic of drug-DNA complexes allows a direct comparison with MS/MS experiments.

The intercalation binding mode of these ligands was demonstrated ${ }^{\circ}$ previously ${ }^{\circ}\left[34,{ }^{\circ} 41,{ }^{\circ} 42\right] .{ }^{\circ}$ Here, ${ }^{\circ}$ two ${ }^{\circ}$ configurations were studied for each intercalation site: the alkyl chain of the drug can be oriented in two directions (Figure $3 a$ ). ${ }^{\circ}$ The ${ }^{\circ}$ central ${ }^{\circ}$ intercalation ${ }^{\circ}$ site ${ }^{\circ}$ is $^{\circ}$ symmetrical and only one orientation of the alkyl chain was studied for the CG*CG intercalation site (to prevent the aminoalkyl chain from going outside the duplex). The planar aromatic rings of the drugs were inserted into the duplex, with the alkyl chain lying in the minor groove allowing interaction between the side chain and the groove ${ }^{\circ}$ of ${ }^{\circ}$ the ${ }^{\circ}$ helix ${ }^{\circ}\left[34,{ }^{\circ} 41,{ }^{\circ} 42\right] .{ }^{\circ}$ Small ${ }^{\circ}$ molecules ${ }^{\circ}$ generally interact via the DNA minor groove because it is narrower and more electronegative than the major groove, providing more favorable interactions with the ligand ${ }^{\circ}[58] . .^{\circ} \mathrm{Only}^{\circ} \mathrm{a}^{\circ} \mathrm{few}^{\circ} \mathrm{drugs}^{\circ} \mathrm{such}^{\circ} \mathrm{as}^{\circ}$ the $\mathrm{b}^{\circ}$ is-intercalator $^{\circ}$ ditercalinium ${ }^{\circ}[59],{ }^{\circ}$ or $^{\circ}$ drugs $^{\circ}$ that $^{\circ}$ have $^{\circ}$ large ${ }^{\circ}$ bulky groups ${ }^{\circ}[60],{ }^{\circ}$ bind $^{\circ}$ to $^{\circ}$ duplex $^{\circ} \mathrm{DNA}^{\circ}$ through ${ }^{\circ}$ the ${ }^{\circ}$ major groove. ${ }^{\circ}$ Figure ${ }^{\circ} 3 b^{\circ}$ shows $^{\circ}$ the ${ }^{\circ}$ geometries ${ }^{\circ}$ of ${ }^{\circ}$ the ${ }^{\circ}$ generated complexes obtained between 2 and the duplex Dk66 after energy minimization. The values of the interaction energies obtained using eq 2 are summarized in Table 1 , together ${ }^{\circ}$ with the ${ }^{\circ} \mathrm{CE}_{50}$ values obtained by MS/MS.

It is noteworthy that the interaction energies calculated for the intercalation sites CG-CG, AT-AT, and CG-AT follow roughly the same ranking order as in the MS/MS experiments. Only the $E_{\text {int }}$ obtained for the intercalation site CG-AT with the aminoalkyl tail oriented toward the GC-side ("up") does not follow the experimental trend. The absence of a significant dependence of interaction energies on the base sequence is in agreement with the absence of sequence selectivity

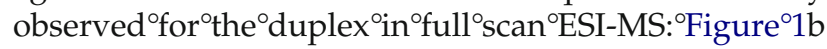
shows that the amount of bound ligand does not change according with the GC content of the duplex. In the population of complexes selected for MS/MS, the probability of the ligand being in GC-rich sites is, therefore, supposed to be proportional to the fraction of these sites. 
(a)

(b)
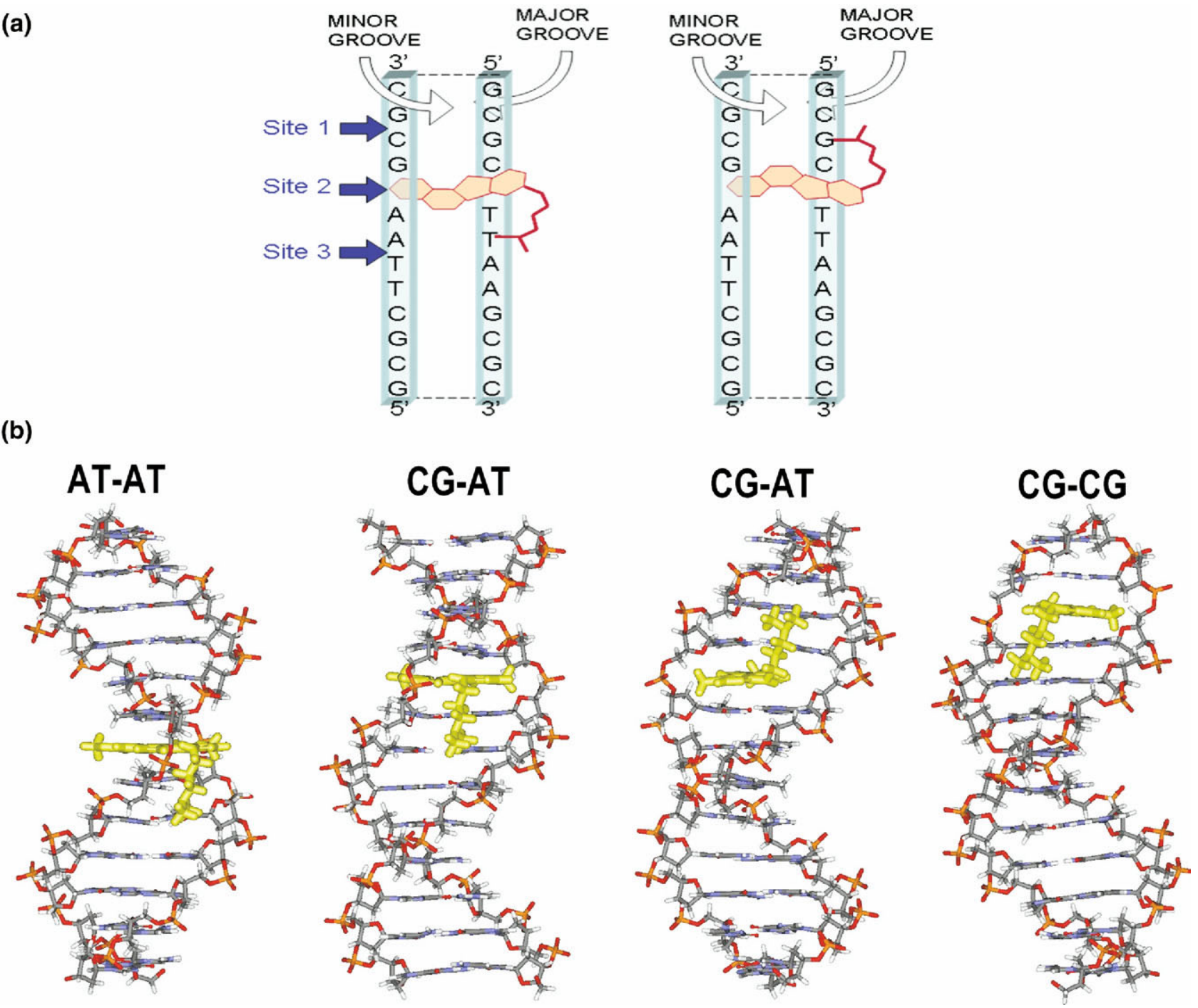

Figure 3. Modeling of duplex-ligand binding sites. (a) Localization of the three intercalation sites used in the molecular modeling. A drug is represented in site 2, with two possible orientations (alkyl chain toward $5^{\prime}$ (down) or $3^{\prime}$ end (up) with respect to the first stand of the duplex). (b) Modeling of the complex between 2 and the duplex Dk66 in the intercalation site AT-AT, CG-AT with the aminoalkyl chain "down," CG-AT with the chain "up," and CG-CG.

Table 1. Interaction energies calculated for each drug and intercalation site in the duplex (CGCGAATTCGCG) ${ }_{2}$

\begin{tabular}{lccccc}
\hline & & \multicolumn{3}{c}{$\mathrm{E}_{\text {int }}(\mathrm{kcal} / \mathrm{mol})$} \\
\cline { 3 - 6 } Drug & $\mathrm{CE}_{50}(\mathrm{~V})$ & CG-CG site & AT-AT site & CG-AT site tail down & CG-AT site tail up \\
\hline \hline 1 & 16.6 & -55.4 & -57.2 & -50.3 & -42.7 \\
2 & 16.2 & -55.5 & -51.2 & -55.9 & -43.0 \\
6 & 11.1 & -51.1 & -51.2 & -49.3 & -43.2 \\
3 & 10.4 & -53.5 & -49.3 & -42.7 & -46.8 \\
4 & 9.6 & -47.1 & -46.3 & -45.9 & -41.0 \\
5 & 9.3 & -47.5 & -45.7 & -45.6 & -43.4 \\
7 & 9.2 & -42.2 & -41.9 & -37.6 & -40.8 \\
\hline
\end{tabular}


(a)
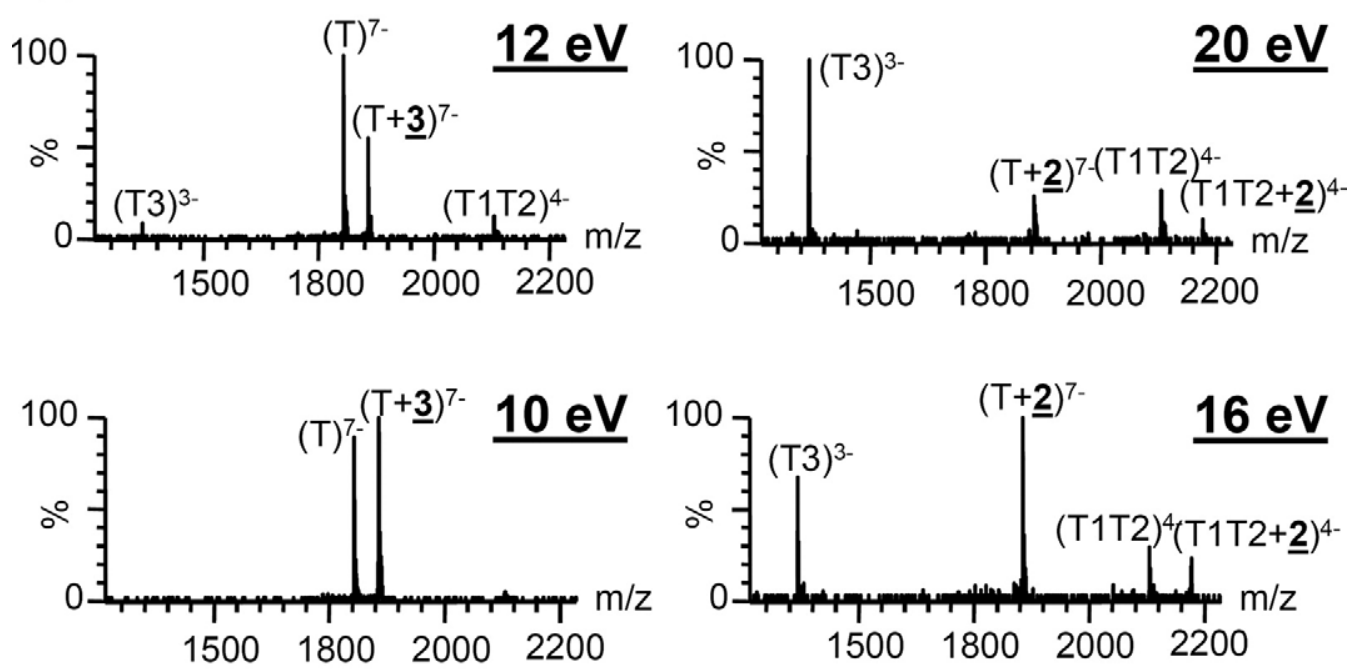

(b)
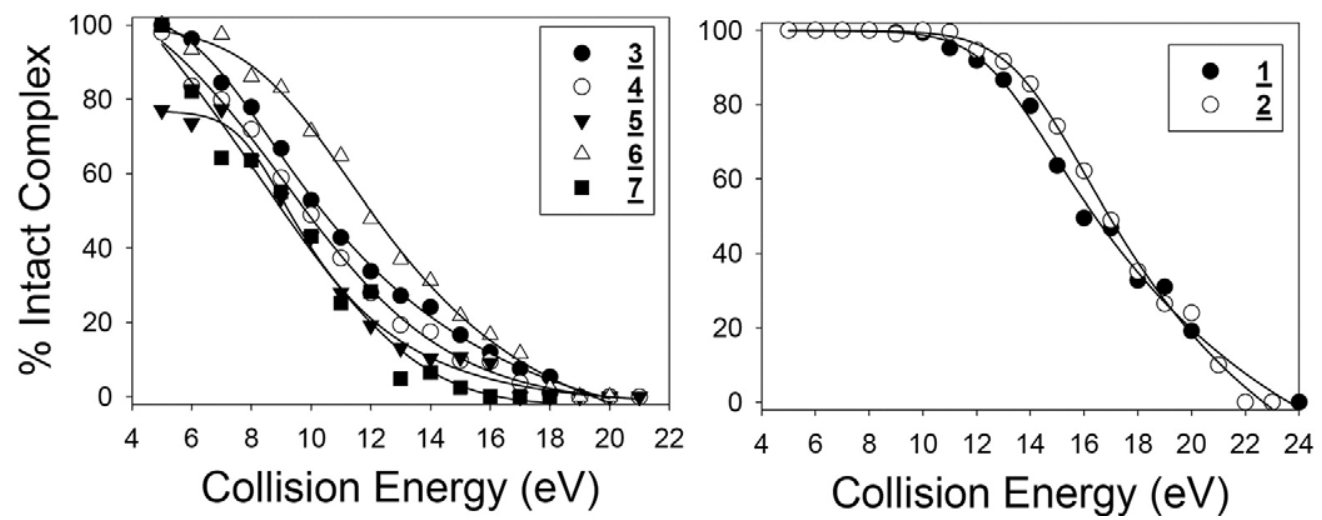

Figure 4. ESI-MS/MS experiments on [1:1 $]^{5-}$ complexes with the triplex. (a) Representative spectra obtained for quinoxaline derivatives (left, shown for ligand 3 at 10 and $12 \mathrm{eV}$ collision energy) and BPIs (right, shown for ligand 2 at 16 and $20 \mathrm{eV}$ collision energy). The argon pressure inside the hexapole collision cell was $3.0 \times 10^{-5}$ mbar. (b) MS/MS breakdown curves of the different drugs with the triplex. The $\%$ of intact complex is calculated using eq 5 for each collision energy.

\section{ESI-MS/MS and Molecular Modeling on the (1:1)} Triplex-Ligand Complexes

Figure $^{\circ} 4 \mathrm{a}^{\circ}$ shows $^{\circ}$ the ${ }^{\circ}$ ESI-MS $/ \mathrm{MS}^{\circ}$ spectra ${ }^{\circ}$ obtained at different collision energies for the BPQ 3 (left) and the BgPI 2 (right). These two families of compounds show two different fragmentation patterns, summarized in Scheme 2. DNA complexes with quinoxaline derivatives dissociate principally via the loss of a neutral drug, while DNA-BPI complexes dissociate mainly

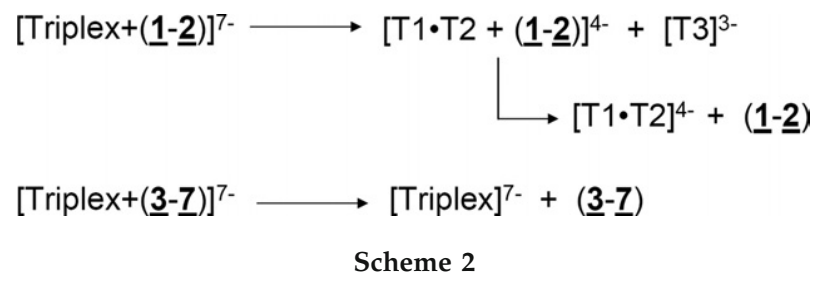$$
\rightarrow[T 1 \cdot T 2]^{4-}+(\underline{1}-\underline{-2})
$$$$
[\text { Triplex+( } \underline{\mathbf{3}}-\underline{\mathbf{7}})]^{7-} \longrightarrow[\text { Triplex] }]^{7-}+(\underline{\mathbf{3}}-\underline{\mathbf{7}})
$$$$
\text { Scheme } 2
$$

via the loss of the antigene strand T3. Some ligand remains bound to the remaining duplex, but free duplex is detected as well. For ligands $3-7$, loss of neutral ligand is almost complete before antigene loss starts, but for ligands $\mathbf{1}$ and 2 . antigene loss occurs at lower energies than loss of neutral ligand. There is, therefore, a competition between loss of neutral ligand and loss of antigene strand $[\mathrm{T} 3]^{3-}$. Loss of neutral ligand occurs at lower collision voltage for ligands $3-7$, while loss of antigene strand occurs at lower collision voltages for ligands 1 and 2.

It must be pointed out that no drug is observed on the antigene strand, suggesting a stronger interaction with the Watson-Crick ${ }^{\circ}$ duplex $^{9}$ part ${ }^{\circ}$ of ${ }^{\text {the }}$ triplex. Figure $4 \mathrm{~b}^{\circ}$ shows $^{\circ}$ the ${ }^{\circ}$ dissociation ${ }^{\circ}$ curves $^{\circ}$ obtained $^{\circ}$ for ${ }^{\circ}$ each drug. The percentage of intact complex is calculated using eq 5, which is valid for both cases (intensities are replaced by zero when appropriate). 
(a)
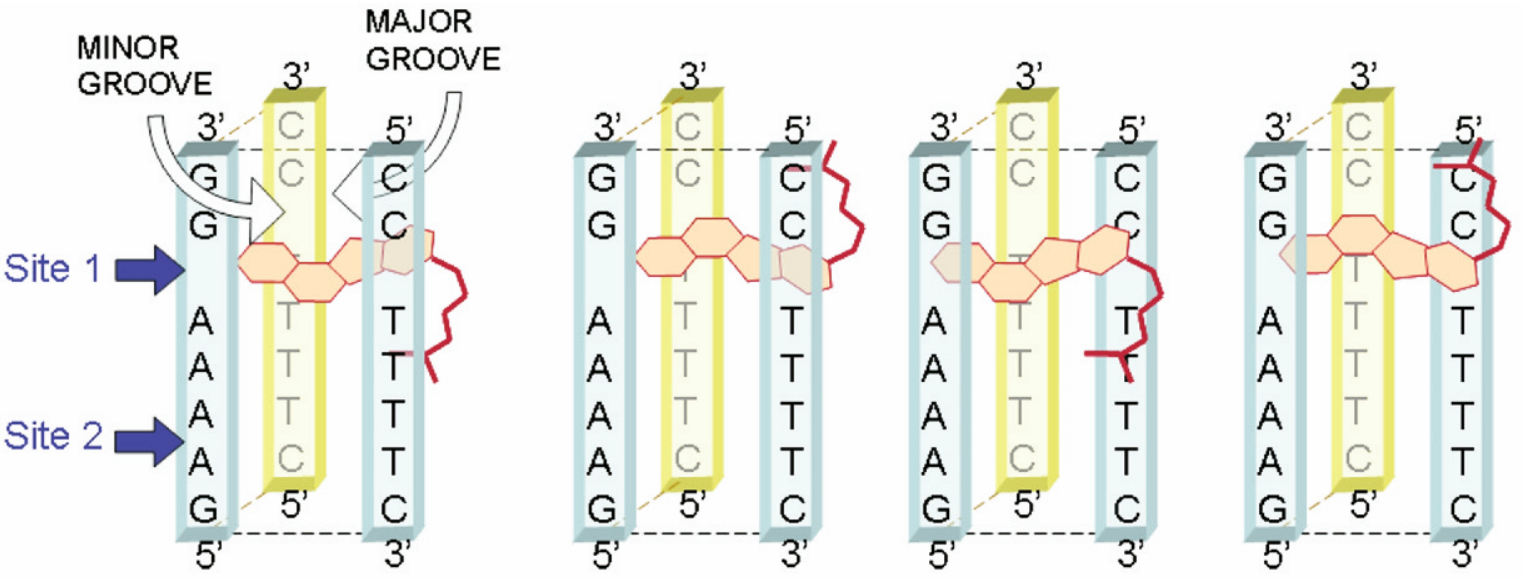

(b)

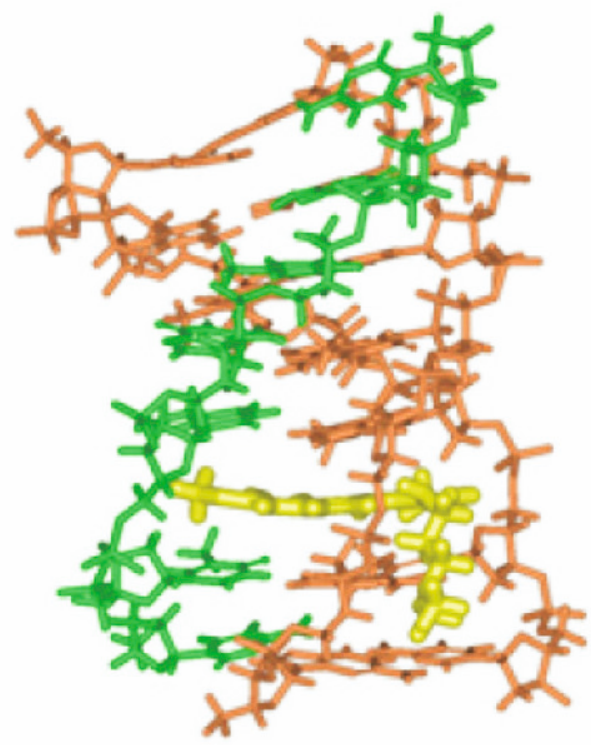

(c)
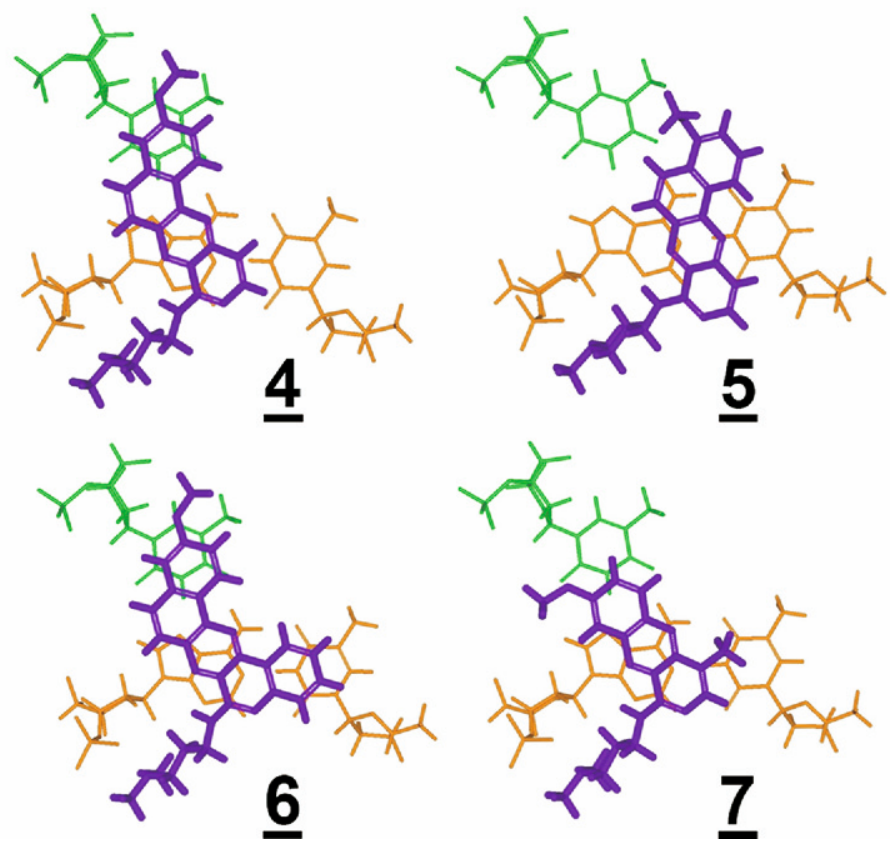

Figure 5. Modeling of duplex-ligand binding sites. (a) Localization of the two intercalation sites used in the molecular modeling. A drug is represented for site 1 . Two orientations of the drug are possible (alkyl chain toward $5^{\prime}$ or $3^{\prime}$ end in respect to the G-rich strand). The drug was docked either by the minor or the major groove of the helix. (b) Energy minimized structure of ligand 2 bound to the triplex (CTTTTCC*GAAAAGG-CTTTTCC), in site 2 (TAT-TAT) with the aminoalkyl chain "down." (c) zoom of the energy-minimized models of 4, 5, 6, 7 intercalated in the TAT-TAT base triplets with the aminoalkyl chain "down." The planar ring system of the ligands is shown stacked with the base triplet. Only the bottom triplet is shown for clarity. The Watson-Crick base pairs are at the bottom left and bottom right corners of each figure, the antigene base is at the top left corner of each figure, and the drug is stacked on top of the three bases.

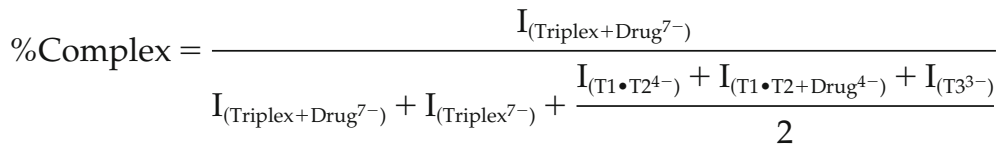

The two different fragmentation pathways do not necessarily imply that the binding modes are different. The breakdown curves of the duplex-ligand complexes also showed a large difference in dissociation threshold between ligands 1 and 2 and 3-7. The different dissoci- ation pathways with the triplex can simply be that the ligand loss threshold is well above the antigene loss threshold for ligands 1 and 2, and well below it for ligands 3-7. However, the fact that the breakdown curves are not strictly parallel is a stronger experimental 
Table 2. Interaction energies calculated for each drug and intercalation site in the Triplex (CTTTTCC*GAAAAGG-CTTTTCC)

\begin{tabular}{|c|c|c|c|c|c|c|c|c|c|}
\hline \multirow[b]{2}{*}{ Drug } & \multirow[b]{2}{*}{$\mathrm{CE}_{50}(\mathrm{~V})$} & \multicolumn{8}{|c|}{$\mathrm{E}_{\mathrm{int}}(\mathrm{kcal} / \mathrm{mol})$} \\
\hline & & $\begin{array}{l}\text { CGC-TAT } \\
\text { Major } \\
\text { groove } \\
\text { tail down }\end{array}$ & $\begin{array}{l}\text { CGC-TAT } \\
\text { Major } \\
\text { groove } \\
\text { tail up }\end{array}$ & $\begin{array}{l}\text { CGC-TAT } \\
\text { Minor } \\
\text { groove } \\
\text { tail down }\end{array}$ & $\begin{array}{c}\text { CGC-TAT } \\
\text { Minor } \\
\text { groove } \\
\text { tail up }\end{array}$ & $\begin{array}{l}\text { TAT-TAT } \\
\text { Major } \\
\text { groove } \\
\text { tail down }\end{array}$ & $\begin{array}{c}\text { TAT-TAT } \\
\text { Major } \\
\text { groove } \\
\text { tail up }\end{array}$ & $\begin{array}{l}\text { TAT-TAT } \\
\text { Minor } \\
\text { groove } \\
\text { tail down }\end{array}$ & $\begin{array}{l}\text { TAT-TAT } \\
\text { Minor } \\
\text { groove } \\
\text { tail up }\end{array}$ \\
\hline 1 & 16.3 & -33.5 & -68.0 & -53.4 & -47.3 & -46.1 & -41.0 & -66.4 & -55.5 \\
\hline 2 & 17.0 & -39.2 & -44.0 & -49.3 & -44.7 & -39.2 & -48.2 & -64.8 & -62.9 \\
\hline 6 & 12.0 & -45.6 & -55.0 & -59.5 & -49.6 & -46.5 & -38.0 & -64.4 & -54.4 \\
\hline 3 & 10.5 & -43.2 & -52.1 & -51.7 & -48.2 & -51.3 & -38.8 & -58.1 & -47.8 \\
\hline 4 & 10.0 & -43.5 & -50.6 & -50.2 & -56.0 & -47.5 & -46.3 & -55.5 & -45.8 \\
\hline 5 & 9.3 & -52.2 & -46.8 & -50.5 & -47.2 & -41.9 & -46.5 & -49.4 & -48.7 \\
\hline 7 & 9.2 & -33.7 & -43.3 & -53.8 & -47.9 & -38.6 & -51.5 & -51.9 & -43.8 \\
\hline
\end{tabular}

Energy minimization to $0.05 \mathrm{kcal} /(\mathrm{mol} . \AA ̊)$ using Polak-Ribiere gradient conjugate optimization algorithm.

argument indicating that different ligands could have different binding modes. Nonparallel curves indicate that the activation entropy of dissociation is different, suggesting that the dissociation mechanisms are different. This could in turn be due to a different binding mode. Note for example the crossing of the breakdown curves ${ }^{\circ}$ of ${ }^{\circ}$ ligands ${ }^{\circ} 1$ and $^{\circ} 2$ in $^{\circ}$ Figure $4 \mathrm{~b},{ }^{\circ}$ left. ${ }^{\circ}$ Among ${ }^{\circ}$ the pyridoquinoxaline drugs 3-7, ligand 6 needs the highest collision energy to be expelled, suggesting it is the best triplex binder of the series.

For the molecular modeling, two intercalation sites were generated using the same procedure as for duplex CGC-TAT and TAT-TAT. Four starting intercalation geometries were generated for each site: two with the drug docked with the alkyl chain in the major groove with the aminoalkyl chain going "up" (i.e., amino group of the alkyl chain toward the $3^{\prime}$ end of the antigene strand) and "down" (aminoalkyl chain toward the $5^{\prime}$ end of the antigene strand), and two by intercalating the drug with the alkyl chain in the minor groove, and testing the ${ }^{2} w 0^{\circ}$ orientations ${ }^{\circ}$ of the ${ }^{\circ}$ chain (Figure $5 a$ ). A total of eight binding modes were, therefore, tested for each drug. We checked that the optimized conformations of the triplex with ligand 4 and 6 were stable in vacuo by running lengthy dynamics simulation (total of $5 \mathrm{~ns}$ ) at the temperature of $300 \mathrm{~K}$ (data not shown). Although the helical conformation is slightly distorted (especially the $3^{\prime}$ end of the antigene strand), hydrogen bonding in the base triplets involved in the ligand binding site is well conserved, and ligand binding mode remains $^{\circ}$ the $^{\circ}$ same $^{\circ}$ as $^{\circ}$ shown $^{\circ}$ in $^{\circ}$ Figure $^{\circ} 5 c^{,}$, thereby validating our modeling approach.

The calculated interaction energies for the different binding $^{\circ}$ sites $^{\circ}$ are $^{\circ}$ summarized $^{\circ}$ in $^{\circ}$ Table $^{\circ} 2^{\circ}$ with $^{\circ}$ the corresponding experimental voltage to observe $50 \%$ dissociation $\left(\mathrm{CE}_{50}\right)$ obtained by tandem mass spectrometry. The calculated interaction energies are the most favorable for the TAT-TAT binding site with the aromatic rings of the drugs inserted through the minor groove of the Watson-Crick duplex and the aminoalkyl chain in the minor groove. For that binding site, the interaction energies follow the same ranking as the experimentally determined $\mathrm{CE}_{50}\left(\right.$ Table $\left.^{\circ} 2\right){ }^{\circ}$ Figure $^{\circ} 5 \mathrm{~b}$ shows the structure of the complex with ligand 2 in that binding ${ }^{\circ}$ mode, ${ }^{\circ}$ and ${ }^{\circ}$ Figure $^{\circ} 5 c^{\circ}$ shows ${ }^{\circ}$ the ${ }^{\circ}$ superimposition of the ligand and the base triplet for ligands 4-7. The only exception is ligand $\mathbf{1}$, for which a significantly lower energy site corresponds to the aminoalkyl chain in the major groove. In previous structure-affinity relationships and molecular modeling for BePI and BgPI derivatives, it was already suggested that the aminoalkyl chain was located in the minor groove of the duplex for BgPIs like 2 and in the major groove together with the ${ }^{\circ}$ antigene ${ }^{\circ}$ strand $^{\circ}$ for $^{\circ} \mathrm{BePIs}^{\circ}{ }^{\circ}$ ike $^{\circ} \mathbf{1}$ [34]..$^{\circ} \mathrm{Our}^{\circ}$ calculations are also in line with this model and, coming back to the MS/MS results, the fact that the breakdown curves of ligands 1 and 2 are not parallel can now be interpreted as an influence of the ligand binding mode on the activation entropy of dissociation. This illustrates that (1) a careful interpretation of the breakdown curves allows guessing that two of the ligands might have different binding modes, and (2) molecular modeling calculations, even at the modest level used here, could allow identifying the correct binding mode.

\section{Conclusions}

The major conclusions of the present work are as follows. The benzopyridoindoles (1 and 2 ) have larger interaction energies than the pyridoquinoxalines (3-7). The nature of the heteroaromatic rings, therefore, plays a major role in the affinity of the ligand for the target. However, the benzopyridoindoles do not show any selectivity for the triplex compared with the duplex (see Figure ${ }^{\circ}$ ). ${ }^{\circ}$ Molecular ${ }^{\circ}$ modeling $^{\circ}$ indeed ${ }^{\circ}$ shows ${ }^{\circ}$ that ${ }^{\circ}$ BPI drugs interact preferentially with the Watson-Crick duplex and have small interaction with the antigene strand. Among the benzopyridoquinoxalines, the three most selective ligands $(4,5$, and 6$)$ all share the same heteroaromatic core, which best stacks on a base triplet $\left(\right.$ see $^{\circ}$ Figure $\left.^{\circ} 5\right){ }^{\circ}{ }^{\circ}$ Ligand $^{\circ} 4$ has $^{\circ}$ stronger ${ }^{\circ}$ interaction ${ }^{\circ}$ with the base triplet than isomers 7 and 5. Our results consistently suggest that ligand 6 is the most promising lead for triplex-selective ligands. It has (1) the best 
triplex specificity, as shown by the ESI-MS screening (Figure 1 1), ${ }^{\circ}(2)^{\circ}$ the highest ${ }^{\circ}$ interaction ${ }^{\circ}$ energy $^{\circ}$ of ${ }^{\circ}$ all ${ }^{\circ} \mathrm{BPQs}$

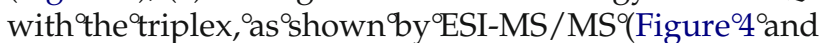
Table 2 ), ${ }^{\circ}$ and $^{\circ}(3)^{\circ}$ the $^{\circ}$ most $^{\circ}$ favorable ${ }^{\circ}$ stacking ${ }^{\circ}$ configuration on a base triplet, as shown by molecular modeling (Figure $\left.{ }^{\circ} 5 \mathrm{c}\right){ }^{\circ}{ }^{\circ}$ This ${ }^{\circ}$ study $^{\circ}$ demonstrates $^{\circ}$ for $^{\circ}{ }^{\circ}{ }^{\circ}{ }^{\circ}$ first ${ }^{\circ}$ time the use of ESI-MS and ESI-MS/MS to study drugtriplex interactions, and underlines the utility of molecular modeling for the interpretation of tandem mass spectrometry data in structural terms.

\section{Acknowledgments}

This work was supported by the FRS-FNRS (Fonds de la Recherche Scientifique-FNRS) via a Research Associate position to VG and a Postdoctoral fellowship to FR. The authors thank Dr. Christian Bailly, Dr. Jean-Louis Mergny, and Dr. Patrizia Alberti for helpful discussion.

\section{References}

1. Hurley, L. H. DNA and Its Associated Processes as Targets for Cancer Therapy. Nat. Rev. Cancer 2002, 2, 188-200.

2. Hélène, C. The Antigene Strategy: Control of Gene Expression by Triplex-Forming Oligonucleotides. Anticancer Drug Des 1991, 6, 569584 .

3. Plum, G. E.; Pilch, D. S.; Singleton, S. F.; Breslauer, K. J. Nucleic Acid Hybridization: Triplex Stability and Energetics. Annu. Rev. Biophys. Biomol. Struct. 1995, 24, 319-350.

4. Jenkins, T. C. Targeting Multistranded DNA Structures. Curr. Med. Chem. 2000, 7, 99-115.

5. Opalinska, J. B.; Gewirtz, A. M. Nucleic Acid Therapeutics: Basic Principles and Recent Applications. Nature Rev. Drug. Discov. 2002, 1, 503-514

6. Besch, R.; Giovannangeli, C.; Degitz, K. Triplex-Forming oligonucleotides-Sequence-Specific DNA Ligands as Tools for Gene Inhibition and for Modulation of DNA-Associated Functions. Current Drug Targets 2004, 5, 691-703.

7. Felsenfeld, G.; Davis, D. R.; Rich, A. Formation of a Three-Stranded Polynucleotide Molecule. I. Am. Chem. Soc. 1957, 79, 2023-2024.

8. Marchand, C.; Bailly, C.; Nguyen, C. H.; Bisagni, E.; Garestier, T.; Helene, C.; Waring, M. J. Stabilization of Triple Helical DNA by a Benzopynidoquinoxaline Intercalator. Biochemistry 1996, 35, 5022-5032.

9. Zain, R.; Marchand, C.; Sun, J. S.; Nguyen, C. H.; Bisagni, E.; Garestier, T.; Helene, C. Design of a Triple-Helix-Specific Cleaving Reagent. Chem. Biol. 1999, 6, 771-777.

10. Eftink, M. R. Fluorescence Methods for Studying Equilibrium Macromolecule-Ligand Interactions. Methods Enzymol. 1997, 278, 221-257.

11. Chaires, J. B. Analysis and Interpretation of Ligand-DNA Binding Isotherms. Methods Enzymol. 2001, 340, 3-23.

12. Chaires, J. B. Structural Selectivity of Drug-Nucleic Acid Interactions Probed by Competition Dialysis. DNA Binders and Related Subjects. Topics Curr. Chem. 2005, 253, 33.-53.

13. Chaires, J. B. Competition Dialysis: An Assay to Measure the Structural Selectivity of Drug-Nucleic Acid Interactions. Curr. Med. Chem. Anticancer Agents 2005, 5, 339-352.

14. Piehler, J.; Brecht, A.; Gauglitz, G.; Zerlin, M.; Maul, C.; Thiericke, R.; Grabley, S. Label-Free Monitoring of DNA-Ligand Interactions. Anal. Biochem. 1997, 249, 94-102.

15. Myszka, D. G.; Jonsen, M. D.; Graves, B. J. Equilibrium Analysis of High Affinity Interactions using BIACORE. Anal. Biochem. 1998, 265, 326-333.

16. Freire, E.; Mayorge, O. L.; Straume, M. Isothermal titration calorimetry. Anal. Chem. 1990, 950, A-959 A

17. Breslauer, K. J.; Freire, E.; Straume, M. Calorimetry: A tool for DNA and Ligand-DNA Studies. Methods Enzymol. 1992, 211, 533-567.

18. Gale, D. C.; Goodlett, D. R.; Light-Wahl, K. J.; Smith, R. D. Observation of Duplex DNA-Drug Noncovalent Complexes by Electrospray Ionization Mass Spectrometry. J. Am. Chem. Soc. 1994, 116, 6027-6028

19. Gale, D. C.; Smith, R. D. Characterization of Noncovalent Complexes Formed Between Minor Groove Binding Molecules and Duplex DNA by Electrospray Ionization Mass Spectrometry. J. Am. Soc. Mass Spectrom. 1995, 6, 1154-1164.

20. Pocsfalvi, G.; Di Landa, G.; Ferranti, P.; Ritieni, A.; Randazzo, G.; Marorni, A. Observation of Noncovalent Interactions Between Beauvericin and Oligonucleotides Using Electrospray Ionization Mass Spectrometry. Rapid Commun. Mass Spectrom. 1997, 11, 265-272.

21. Triolo, A.; Arcamone, F. M.; Raffaelli, A.; Salvadori, P. Noncovalent Complexes Between DNA-Binding Drugs and Double-Stranded Deoxyoligonucleotides: A Study by Ion-Spray Mass Spectrometry. J. Mass Spectrom. 1997, 32, 1186-1194.
22. Gabelica, V.; De Pauw, E.; Rosu, F. Interaction Between Antitumor Drugs and Double-Stranded DNA Studied by Electrospray Ionization Mass Spectrometry. J. Mass Spectrom. 1999, 34, 1328-1337.

23. Kapur, A.; Beck, J. L.; Sheil, M. M. Observation of Daunomycin and Nogalamycin Complexes with Duplex DNA Using Electrospray Ionization Mass Spectrometry. Rapid Commun. Mass Spectrom. 1999, 13, 2489 2497.

24. Wan, K. X.; Shibue, T.; Gross, M. L. Noncovalent Complexes Between DNA-Binding Drugs and Double-Stranded Oligodeoxynucleotides: A Study by Electrospray Ionization Mass Spectrometry. J. Am. Chem. Soc. 2000, 122, 300-307.

25. Reyzer, M.; Brodbelt, J. S.; Kerwin, S. M.; Kumar, D. Evaluation of Complexation of Metal-Mediated DNA-Binding Drugs to Oligonucleotides Via Electrospray Ionization Mass Spectrometry. Nucleic Acids Res. 2001, 29, e103.

26. Beck, J.; Colgrave, M. L.; Ralph, S. F.; Sheil, M. M. Electrospray Ionization Mass Spectrometry of Oligonucleotide Complexes with Drugs, Metals, and Proteins. Mass Spectrom. Rev. 2001, 20, 61-87.

27. Rosu, F.; Gabelica, V.; Houssier, C.; De Pauw, E. Determination of Affinity, Stoichiometry and Sequence Selectivity of Minor Groove Binder Complexes with Double-Stranded Oligodeoxynucleotides by Electrospray Ionization Mass Spectrometry. Nucleic Acids Res. 2002, 30, e82.

28. Guittat, L.; De Cian, A.; Rosu, F.; Gabelica, V.; De Pauw, E.; Delfourne, E.; Mergny, J. L. Ascididemin and Meridine Stabilize G-quadruplexes and Inhibit Telomerase In Vitro. Biochim. Biophys. Acta. 2005, 1724, 375-384.

29. Guittat, L.; Alberti, P.; Rosu, F.; Van Miert, S.; Thetiot, E.; Pieters, L.; Gabelica, V.; De Pauw, E.; Ottaviani, A.; Riou, J.-F.; Mergny, J.-L. Interactions of Cryptolepine and Neocryptolepine with Unusual DNA Structures. Biochimie 2003, 85, 535-547.

30. Rosu, F.; De Pauw, E.; Guittat, L.; Alberti, P.; Lacroix, L.; Mailliet, P.; Riou, J.-F.; Mergny, J.-L. Selective Interaction of Ethidium Derivatives with Quadruplexes. An Equilibrium Dialysis and Electrospray Ionization Mass Spectrometry Analysis. Biochemistry 2003, 42, 10361-10371.

31. Carrasco, C.; Rosu, F.; Gabelica, V.; Houssier, C.; De Pauw, E.; GarbayJaureguiberry, C.; Roques, B.; Wilson, W. D.; Chaires, J. B.; Waring, M. J.; Bailly, C. Tight Binding of the Antitumor Drug Ditercalinium to Quadruplex DNA. Chem. Biochem. 2002, 3, 100-106.

32. Mazzitelli, C. L.; Brodbelt, J. S.; Kern, J. T.; Rodriguez, M.; Kerwin, S. M. Evaluation of Binding of Perylene Diimide and Benzannulated Perylene Diimide Ligands to DNA by Electrospray Ionization Mass Spectrometry. J. Am. Soc. Mass Spectrom. 2006, 17, 593-604.

33. Nguyen, C. H.; Lhoste, J. M.; Lavelle, F.; Bissery, M. C.; Bisagni, E. Synthesis and Antitumor-Activity of 1-[[(dialkylamino)alkyl]amino]-4methyl-5h-pyrido[4,3-B]benzo[e])indole and 1-[[dialkylamino)alky1]amino]-4-methyl-5h-pyrido[4,3-B]-benzo[g])indole-A New Class of Antineoplastic Agents. J. Med. Chem. 1990, 33, 1519-1528.

34. Escudé, C.; Nguyen, C. H.; Mergny, J.-L.; Sun, J.-S.; Bisagni, E.; Garestier, T.; Hélène, C. Selective Stabilization of DNA Triple Helices by Benzopyridoindole Derivatives. J. Am. Chem. Soc. 1995, 117, 1021210219.

35. Pilch, D. S.; Waring, M. J.; Sun, J.-S.; Rougée, M.; Nguyen, C. H.; Bisagni, E.; Garestier, T.; Hélène, C. Characterization of a Triple Helix-Specific Ligand BePI (3-metoxy-7h-8-methyl-11-[(3'-amino)propylamino]-benzo[e]pyrido[4,3-b]indole) intercalates into both double-helical and triple-helical DNA. J. Mol. Biol. 1993, 232, 926-946.

36. Bailly, C.; Marchand, C.; Nguyen, C. H.; Bisagni, E.; Garestier, T.; Helene, C.; Waring, M. J. Localized Chemical-Reactivity in DoubleStranded DNA Associated with the Intercalative Binding of Benzo[E]Pyridoindole and Benzo[G]Pyridoindole Triple-Helix-Stabilizing Ligands. Eur. J. Biochem. 1995, 232, 66-76.

37. Mergny, J.-L.; Duval-Valentin, G.; Nguyen, C. H.; Perrouault, L.; Faucon, B.; Rougée, M.; Montenay-Garestier, T.; Bisagni, E.; Hélène, C. Triple Helix-Specific Ligands. Science 1992, 256, 1681-1684.

38. Riou, J. F.; Fosse, P.; Nguyen, C. H.; Larsen, A. K.; Bissery, M. C.; Grondard, L.; Saucier, J. M.; Bisagni, E.; Lavelle, F. Intoplicine (Rp60475) and Its Derivatives, a New Class of Antitumor Agents Inhibiting Both Topoisomerase-I and Topoisomerase-II Activities. Cancer Res. 1993, 53, 5987-5993.

39. Nguyen, C. H.; Fan, E.; Riou, J.-F.; Bissery, M.-C.; Vrignaud, P.; Lavelle, F.; Bisagni, E. Synthesis and Biological Evaluation of Amino-Substituted benzo[f]pyrido[4,3-b] and pyrido[3,4-b]quinoxalines: A New Class of Antineoplastic Agents. Anticancer Drug Des. 1995, 10, 277-297.

40. Marchand, C.; Bailly, C.; Nguyen, C. H.; Bisagni, E.; Garestier, T.; Hélène, C.; Waring, M. J. Stabilization of Triple Helical DNA by a Benzopyridoquinoxaline Intercalator. Biochemistry 1996, 35, 5022-5032.

41. Pilch, D. S.; Martin, M.-T.; Nguyen, C. H.; Sun, J.-S.; Bisagni, E.; Garestier, T.; Hélène, C. Self-Association and DNA-Binding Properties of Two Triple Helix-Specific Ligands: Comparison of a Benzo[e]pyridoindole and a Benzo[g]pyridoindole. J. Am. Chem. Soc. 1993, 115, 9942 9951.

42. Nabiev, I.; Chourpa, I.; Riou, J. F.; Nguyen, C. H.; Lavelle, F.; Manfait, M. Molecular-Interactions of DNA Topoisomerase-I and Topoisomerase-II Inhibitor with DNA and Topoisomerases and in Ternary Complexes-Binding Modes and Biological Effects for Intoplicine Derivatives. Biochemistry 1994, 33, 9013-9023.

43. Escudé, C.; Nguyen, C. H.; Kukreti, S.; Janin, Y.; Sun, J.-S.; Bisagni, E.; Garestier, T.; Hélène, C. Rational Design of a Triple Helix-Specific Intercalating Ligand. Proc. Natl. Acad. Sci. U.S.A. 1998, 95, 3591-3596. 
44. Vékey, K. Internal Energy Effects in Mass Spectrometry. J. Mass Spectrom. 1996, 31, 445-463.

45. Hase, W. L. Some Recent Advances and Remaining Questions Regarding Unimolecular Rate Theory. Acc. Chem. Res. 1998, 31, 659-665.

46. Lifshitz, C. Some Recent Aspects of Unimolecular Gas Phase Ion Chemistry. Chem. Soc. Rev. 2001, 30, 186-192.

47. Rosu, F.; Gabelica, V.; Houssier, C.; Colson, P.; De Pauw, E. Triplex and Quadruplex DNA Structures Studied by Electrospray Mass Spectrometry. Rapid Commun. Mass Spectrom. 2002, 16, 1729-1736.

48. Gabelica, V.; De Pauw, E. Comparison of the Collision-Induced Dissociation of Duplex DNA at Different Collision Regimes: Evidence for a Multistep Dissociation Mechanism. J. Am. Soc. Mass Spectrom. 2002, 13, 91-98.

49. Kuszewski, J.; Schwieters, C.; Clore, G. M. Improving the Accuracy of NMR Structures of DNA by Means of a Database Potential of Mean Force Describing Base-Base Positional Interactions. J. Am. Chem. Soc. 2001, 123, 3903-3918.

50. Cirilli, M.; Bachechi, F.; Ughetto, G.; Colonna, F. P.; Capobianco, M. L. Interactions Between Morpholinyl Anthracyclines and DNA-the Crystal-Structure of a Morpholino Doxorubicin Bound to D(CGTACG). J. Mol. Biol. 1993, 230, 878-889.

51. Frederick, C. A.; Williams, L. D.; Ughetto, G.; Van der Marel, G. A.; Van Boom, J. H.; Rich, A.; Wang, A. H. Structural Comparison of Anticancer Drug-DNA Complexes: Adriamycin and Daunomycin. Biochemistry 1990, 29, 2538-2549.

52. Radhakrishnan, I.; Patel, D. J. Solution Structure of a Pyrimidine . Purine $\cdot$ Pyrimidine DNA Triplex Containing $\mathrm{T} \cdot \mathrm{At}, \mathrm{C}^{+} \cdot \mathrm{Gc}$, and $\mathrm{G} \cdot \mathrm{Ta}$ Triples. Structure 1994, 2, 17-32.
53. Gabelica, V.; Galic N.; Rosu F.; Houssier C.; De Pauw, E. Influence of Response Factors on Determining Equilibrium Association Constants of Noncovalent Complexes by Electrospray Ionization Mass Spectrometry. J. Mass Spectrom. 2003, 38, 491-501.

54. Rosu, F.; Pirotte, S.; De Pauw, E.; Gabelica, V. Positive and Negative Ion Mode ESI-MS and MS/MS for Studying Drug-DNA Complexes. Int. J. Mass Spectrom. 2006, 253, 156-171.

55. Bostock-Smith, C. E.; Harris, S. A.; Laughton, C. A.; Searle, M. S. Induced Fit DNA Recognition by a Minor Groove Binding Analogue of Hoechst 33258: Fluctuations in DNA A Tract Structure Investigated by NMR and Molecular Dynamics Simulations. Nucleic Acids Res. 2001, 29, 693-702.

56. Chaires, J. B.; Satyanaraana, S.; Suh, D.; Fokt, I.; Przewloka, T.; Priebe, W. Parsing the Free Energy of Anthracycline Antibiotic Binding to DNA. Biochemistry 1996, 35, 2047-2053.

57. Harris, S. A.; Gavathiotis, E.; Searle, M. S.; Orozco, M.; Laughton, C. A. Cooperativity in Drug-DNA recognition: A Molecular Dynamics Study. J. Am. Chem. Soc. 2001, 123, 12658-12663.

58. Hannon, M. J. Supramolecular DNA Recognition. Chem. Soc. Rev. 2007, 36, 280-295.

59. Gao, Q.; Williams, L. D.; Egli, M.; Rabinovitch, D.; Chen, S.-L.; Quigley, G. J.; Rich, A. Drug-Induced DNA Repair: X-ray Structure of a DNADitercalinium Complex. Proc. Natl. Acad. Sci. U.S.A. 1991, 88, 2422-2426.

60. Jin, E.; Katritch, V.; Olson, W. K.; Kharatisvili, M.; Abagyan, R.; Plich, D. S. Aminoglycoside Binding in the Major Groove of Duplex RNA: The Thermodynamic and Electrostatic Forces that Govern Recognition. J. Mol. Biol. 2000, 95-110. 